\title{
Assessment and comparison of three different air quality indices in China
}

\author{
Youping $\mathrm{Li}^{\dagger}$, Ya Tang, Zhongyu Fan, Hong Zhou, Zhengzheng Yang \\ College of Environmental Science and Engineering, China West Normal University, Nanchong 637009, China
}

\begin{abstract}
Air pollution index (API) is used in Mainland China and includes only $\mathrm{SO}_{2}, \mathrm{NO}_{2}$ and $\mathrm{PM}_{10}$. In 2016, air quality index (AQI) replaced $\mathrm{API}$. AQI contains three more air pollutants $\left(\mathrm{CO}, \mathrm{O}_{3}\right.$ and $\left.\mathrm{PM}_{2.5}\right)$. Both the indices emphasize on the effect of a single pollutant, whereas the contributions of all other pollutants are ignored. Therefore, in the present work, a novel air quality index (NAQI), which emphasizes on all air pollutants, has been introduced for the first time. The results showed that there were $19 \mathrm{~d}(5.2 \%)$ in API, $28 \mathrm{~d}(7.7 \%)$ in AQI and $183 \mathrm{~d}(50.1 \%)$ in NAQI when the indices were more than 100. In API, $\mathrm{PM}_{10}$ and $\mathrm{SO}_{2}$ were regarded as the primary pollutants, whereas all five air pollutants in AQI were regarded as primary. Furthermore, four air pollutants (other than the $\mathrm{CO}$ ) in NAQI were regarded as primary pollutants. PM $\mathrm{M}_{10}$, as being the primary pollutant, contributed greatly in these air quality indices, and accounted for $51.2 \%$ (API), 37.0\% (AQI) and 52.6\% (NAQI). The results also showed that particulate matter pollution was significantly high in Luzhou, where stricter pollution control measures should be implemented.
\end{abstract}

Keywords: Air pollution index, Air quality index, Luzhou, Particulate matter

\section{Introduction}

Air is one of those fundamental necessities, without which life cannot exist in its current form. Nevertheless, urban ambient air quality is decreasing due to industrialization and urbanization in China [1-2]. Periods of haze and dust have made Chinese people feel anxious for the quality of ambient air. In order to keep the citizens informed of the urban air quality, many cities assess air quality through air quality monitoring networks, which continuously record the mass concentrations of different air pollutants [3]. The concentrations of several criteria pollutants can be included in the air pollution index (API), which is easy to be understood by the public. API and air quality index (AQI) have been used to obtain and convey information regarding the urban air quality in a number of countries and zones worldwide [4].

Bodnar et al. [5] used the index methodology proposed by Bruno and Cocchi (BC Indices) to compare the air quality in Italy, Germany and Poland, and proposed to have a unique, unanimous index in Europe. Based upon the relationship between the health risk and the concentrations of different air pollutants, Cairncross et al. [6] developed a novel air pollution index. Cheng et al. [7] revised the air quality index for $\mathrm{PM}_{2.5}$ according to entropy principle, and compared it with Pollutant Standard Index (PSI) and AQI. The revised air quality index (RAQI) not only demonstrated higher accuracy, but also distinguished different pollution episodes. In order to represent the global ambient air quality, Cooper et al. [8] developed a satellite-based multi-pollutant index for the concentrations of $\mathrm{PM}_{2.5}$ and $\mathrm{NO}_{2}$. In short, there are numerous reports in the literature, which detail the comparison and assessment of ambient air quality using different kinds of air pollution or air quality indices [9-15].

API and AQI usually include several air pollutants, such as $\mathrm{SO}_{2}, \mathrm{NO}_{2}$, TSP, $\mathrm{PM}_{10}, \mathrm{PM}_{2.5}, \mathrm{CO}, \mathrm{O}_{3}, \mathrm{~Pb}$ and VOCs. In Mainland China, only three criteria air pollutants, namely the $\mathrm{SO}_{2}, \mathrm{NO}_{2}$ and $\mathrm{PM}_{10}$, are used to calculate API, which is based on National Ambient Air Quality Standard (NAAQS, GB3095-1996) that was issued in 1996 [16]. Due to the drastic increase in the number of vehicles, air pollution has become a serious concern due to their exhaust emissions. In the US, Korea, Hong Kong and other countries, CO and $\mathrm{O}_{3}$ have already been included in the API and AQI since past few years [12]. Due to this reason, the Chinese government issued AQI guideline on January 1, 2016, which was strict, objective
This is an Open Access article distributed under the terms of the Creative Commons Attribution Non-Commercial License (http://creativecommons.org/licenses/by-nc/3.0/) which permits unrestricted non-commercial use, distribution, and reproduction in any medium, provided the original work is properly cited.
Received January 17, 2017 Accepted July 3, 2017

${ }^{\dagger}$ Corresponding author

Email: lyp920@163.com

Tel: +86-817-2568455 Fax: +86-817-2568455

Copyright (C) 2018 Korean Society of Environmental Engineers 
and accurate for the evaluation of results. Both API and AQI consider only the maximum values of sub-indices, and discard the values of other sub-indices and synergistic effects of other air pollutants [17]. Therefore, an attempt has been made to build a novel air quality index (NAQI), which is based on combined effects and weights of different air pollutants. In this paper, based on the data for the concentrations of five air pollutants collected in 2009 (365 d) in Luzhou, both the comparison and assessment of three different air-quality indices (API, AQI and NAQI) are presented and discussed.

\section{Methodology}

\subsection{Sample Location and Data Collection}

There are 5,543 valuable air quality monitoring data points in Luzhou, China. As per 2009, these data points consisted of four monitoring sites (Jiushi Mountain (JS), Xiaoshi Duck (XS), Zhongshan Monitoring Station (ZS), Lantian Bridge (LT)), which extended from north to south across the central part of the city (Fig. 1). Since the JS site is regarded as a background site, the data from this monitoring station was not considered in this work. Average daily mass concentrations of $\mathrm{SO}_{2}, \mathrm{NO}_{2}, \mathrm{PM}_{10}, \mathrm{CO}$ and $\mathrm{O}_{3}$ were recorded using ambient air successive auto monitoring. The monitoring methods used were the ones recommended by the Environmental Protection Ministry of China.

\subsection{API Calculations}

The data were used to calculate the API, whereas the reference scale values are reported in Table 1. The calculation of API was carried out accordingly to Eq. (1) and Eq. (2).

$$
\begin{gathered}
A P I=\max \left(A P I_{1}, A P I_{2}, \ldots, A P I_{n}\right) \\
A P I_{i}=\frac{A P I_{h}-A P I_{l}}{c_{h}-c_{l}}\left(c_{i}-c_{l}\right)+A P I_{l}
\end{gathered}
$$

where $A P I_{i}$ is the sub-index of pollutant $i, c_{i}$ is the mean concentration of the pollutant $i, C_{l}$ is the break point $\leq C_{i}, c_{h}$ is the break point $>c_{i}, A P I_{h}$ and $A P I_{l}$ are the API values when the concentration values are $C_{l}$ and $C_{h}$ (respectively), and $n$ is the number of pollutants. When the API value was less than or equal to 50, the air quality was considered to be good, and nothing was regarded as the primary

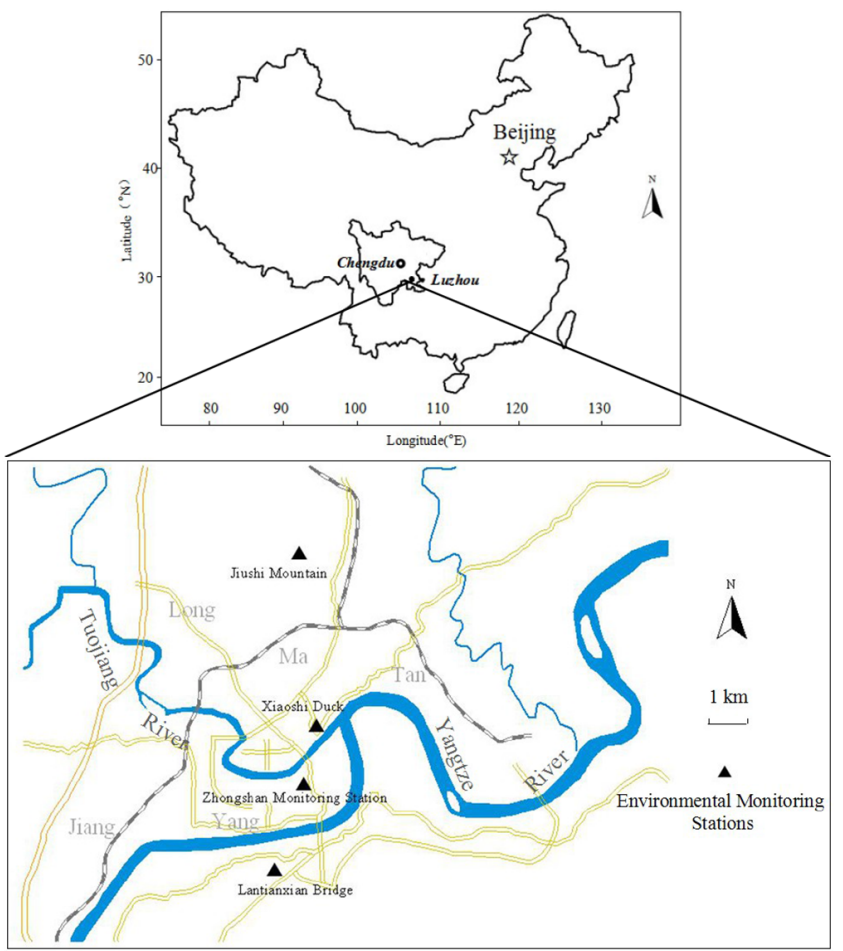

Fig. 1. Location of the environmental monitoring sites in Luzhou City.

pollutant. However, when the API value was higher than 50, the pollutant which had the maximum $A P I_{i}$ was regarded as the primary pollutant. If the $A P I_{i}$ values of air pollutants were the same, the pollutant which was in turn of $\mathrm{SO}_{2}, \mathrm{NO}_{2}, \mathrm{PM}_{10}, \mathrm{CO}, \mathrm{O}_{3}$ and $\mathrm{PM}_{2.5}$ was regarded as the primary pollutant.

\subsection{AQI Calculations}

The method to calculate AQI is the same as API except that the mass concentration limits of these air pollutants were different. The AQI values, their description and corresponding concentrations are listed in Table 1. There are six air pollutants, namely the $\mathrm{SO}_{2}$, $\mathrm{NO}_{2}, \mathrm{PM}_{10}, \mathrm{CO}, \mathrm{O}_{3}$ and $\mathrm{PM}_{2.5}$. The concentration data of $\mathrm{PM}_{2.5}$ was not included as $\mathrm{PM}_{2.5}$ sub-index was not considered for calculating AQI, and thus was not monitored. This shortcoming was rectified as the mass concentration of $\mathrm{PM}_{2.5}$ was started to be monitored from October 2013 onwards.

\begin{tabular}{|c|c|c|c|c|c|c|c|c|c|c|}
\hline \multirow{2}{*}{ Value } & \multirow{2}{*}{ Grade } & \multirow{2}{*}{ Description } & \multicolumn{5}{|c|}{ AQI } & \multicolumn{3}{|c|}{ API } \\
\hline & & & $\mathrm{SO}_{2}$ & $\mathrm{NO}_{2}$ & $\mathbf{P M}_{10}$ & CO & $\mathbf{O}_{3}$ & $\mathrm{SO}_{2}$ & $\mathrm{NO}_{2}$ & $\mathbf{P M}_{10}$ \\
\hline $0-50$ & I & Good & 50 & 40 & 50 & 2,000 & 100 & 50 & 80 & 50 \\
\hline $51-100$ & II & Moderate & 150 & 80 & 150 & 4,000 & 160 & 150 & 120 & 150 \\
\hline $101-150$ & III & $\begin{array}{c}\text { Unhealthy for } \\
\text { sensitive people }\end{array}$ & 475 & 180 & 250 & 14,000 & 215 & 475 & 180 & 250 \\
\hline $151-200$ & IV & Unhealthy & 800 & 280 & 350 & 24,000 & 265 & 800 & 280 & 350 \\
\hline $201-300$ & $\mathrm{~V}$ & Very unhealthy & 1,600 & 565 & 420 & 36,000 & 800 & 1,600 & 565 & 420 \\
\hline $301-500$ & VI & Hazardous & 2,620 & 940 & 600 & 60,000 & - & 2,620 & 940 & 600 \\
\hline
\end{tabular}

Table 1. AQI and API Value, Description and Their Corresponding Mass concentration $\left(\mathrm{\mu g} / \mathrm{m}^{3}\right)$ 


\subsection{NAQI Calculations}

Both API and AQI are based on the concentration limits of air pollutants. However, AQI is easier to be understood. Furthermore, more countries and regions of the world use AQI to get information on the ambient urban air quality. The complexity of the calculating method and disregarding other air pollutants besides the ones having highest API or AQI values are the main shortcomings of API and AQI indices [18]. The process of calculating AQI is shown in Fig. 2. In fact, the mass concentration limits of air pollutants are very important. When AQI or API value was less than 100, the limit value was equal to Grade-II mass concentration value in the National Ambient Air Quality Standard (NAAQS, GB3095-2012), as listed in Table 2. With improvement of environmental quality and the enhancement of environmental consciousness, the NAAQS has become stricter and more scientific. In this way, the AQI values became higher, and more significant changes in air quality were observed. The modified NAAQS is divided into six grades, which makes the calculation of AQI a little difficult. On the other hand,

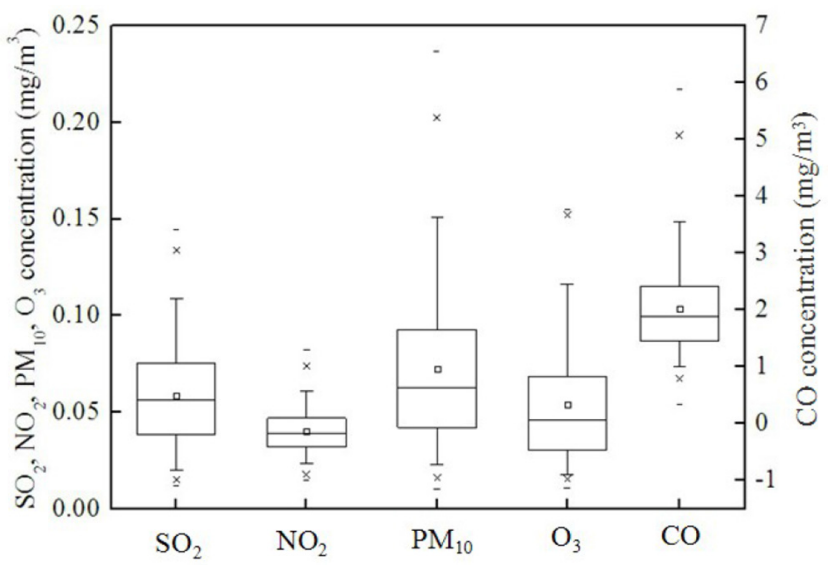

Fig. 2. Mass concentrations of five air pollutants in Luzhou City. the final AQI value of some city or site might be the highest among all the $A Q I_{i}$ values. In such a circumstance, the effect of air pollutant having the maximum $A Q I_{i}$ value on human health also covers the effects of all other air pollutants [19]. For example, when $A Q I_{\mathrm{so} 2}$, $\mathrm{AQI}_{\mathrm{NO} 2}$, and $\mathrm{AQI}_{\mathrm{PM} 10}$ had values of $119,110,120$, respectively, the AQI value was considered to be 120 . The calculating method of AQI is the same as that of the API. Therefore, the $\mathrm{PM}_{10}$ is the primary pollutant among three air pollutants, whereas the $\mathrm{SO}_{2}$, and $\mathrm{NO}_{2}$ are ignored. However, it is widely accepted that both the $\mathrm{SO}_{2}$ and $\mathrm{NO}_{2}$ can have deteriorating impact on the health of humans.

In order to remove these shortcomings in the AQI, a NAQI was introduced in the current study [20]. Eq. (3) - Eq. (5) were used to calculate NAQI.

$$
\begin{gathered}
N A Q I=100 \times \sum_{i=1}^{n} W_{i} P_{i} \\
W_{i}=\frac{\frac{c_{i}}{s_{i}}}{\sum_{i=1}^{n} \frac{c_{i}}{s_{i}}} \\
P_{i}=\frac{c_{i}}{s_{i}}
\end{gathered}
$$

where $N A Q I$ is the AQI of a city or a site, $W_{i}$ is the weight of the pollutant $i, P_{i}$ is the index of the pollutant $i, C_{i}$ is the mean concentration of the pollutant $i$, and $s_{i}$ is the mass concentration value of the pollutant $i$ for Grade-I in NAAQS, respectively. When the API or AQI value was higher than 50, the pollutant which had the maximum $A P I_{i}$ or $A Q I_{i}$ value was regarded as the primary pollutant. If the $A P I_{i}$ or $A Q I_{i}$ values of air pollutants were the same,

\begin{tabular}{|c|c|c|c|c|c|c|}
\hline \multirow[t]{2}{*}{ Air pollutants } & \multirow{2}{*}{$\begin{array}{l}\text { Average } \\
\text { time }\end{array}$} & \multicolumn{2}{|c|}{$\begin{array}{c}\text { Concentration } \operatorname{limit}\left(\mu \mathrm{g} / \mathrm{m}^{3}\right) \\
\text { (GB3095-2012) }\end{array}$} & \multicolumn{3}{|c|}{$\begin{array}{c}\text { Concentration limit }\left(\mu \mathrm{g} / \mathrm{m}^{3}\right) \\
\text { (GB3095-1996) }\end{array}$} \\
\hline & & Grade I & Grade II & Grade I & Grade II & Grade III \\
\hline \multirow{3}{*}{$\begin{array}{l}\text { Sulfur dioxide } \\
\qquad\left(\mathrm{SO}_{2}\right)\end{array}$} & Annual & 20 & 60 & 20 & 60 & 100 \\
\hline & $24 \mathrm{~h}$ & 50 & 150 & 50 & 150 & 250 \\
\hline & $1 \mathrm{~h}$ & 150 & 500 & 250 & 500 & 700 \\
\hline \multirow{3}{*}{$\begin{array}{l}\text { Nitrogen dioxide } \\
\qquad\left(\mathrm{NO}_{2}\right)\end{array}$} & Annual & 40 & 40 & 40 & 40 & 80 \\
\hline & $24 \mathrm{~h}$ & 80 & 80 & 80 & 80 & 120 \\
\hline & $1 \mathrm{~h}$ & 200 & 200 & 120 & 120 & 240 \\
\hline \multirow{2}{*}{$\begin{array}{l}\text { Particulate matter } \\
\qquad\left(\mathrm{PM}_{10}\right)\end{array}$} & Annual & 40 & 70 & 40 & 100 & 150 \\
\hline & $24 \mathrm{~h}$ & 50 & 150 & 50 & 150 & 250 \\
\hline \multirow{2}{*}{$\begin{array}{l}\text { Carbon monoxide } \\
\text { (CO) }\end{array}$} & $24 \mathrm{~h}$ & 4,000 & 4,000 & 4,000 & 4,000 & 6,000 \\
\hline & $1 \mathrm{~h}$ & 10,000 & 10,000 & 10,000 & 10,000 & 20,000 \\
\hline \multirow{2}{*}{$\begin{array}{l}\text { Particulate matter } \\
\qquad\left(\mathrm{PM}_{2.5}\right)\end{array}$} & Annual & 15 & 35 & - & - & - \\
\hline & $24 \mathrm{~h}$ & 35 & 15 & - & - & - \\
\hline
\end{tabular}
the pollutant that was in turn of $\mathrm{SO}_{2}, \mathrm{NO}_{2}, \mathrm{PM}_{10}, \mathrm{CO}, \mathrm{O}_{3}$ and

Table 2. National Ambient Air Quality Standard in China 
$\mathrm{PM}_{2.5}$ was regarded as the primary pollutant. As long as the $P_{i}$ of a pollutant was more than 1.0, the pollutant was regarded as the primary pollutant in NAQI. Eq. (5) was used to calculate $P_{i}$. Similarly, all those pollutants, which had a $P_{\mathrm{i}}$ value of more than 1.0, were considered as the primary pollutants.

\section{Results and Discussion}

\subsection{Variation in Ambient Air Quality}

Fig. 2 shows the annual mean mass concentrations of five air pollutants. The mean concentrations of $\mathrm{SO}_{2}, \mathrm{NO}_{2}, \mathrm{PM}_{10}, \mathrm{CO}$ and $\mathrm{O}_{3}$ were $59 \pm 27,40 \pm 12,72 \pm 40,2,017 \pm 801$ and $54 \pm 31$ $\mu \mathrm{g} / \mathrm{m}^{3}$, respectively. The concentrations of $\mathrm{SO}_{2}$, and $\mathrm{NO}_{2}$ were very close to Grade-II annual mean concentrations of $60 \mu \mathrm{g} / \mathrm{m}^{3}$ and 40 $\mu \mathrm{g} / \mathrm{m}^{3}$, respectively. The concentrations of other three pollutants were much lower than their corresponding annual mean concentration limit values. The concentrations of $\mathrm{SO}_{2}$, $\mathrm{CO}$ and $\mathrm{O}_{3}$ were substantially higher than those reported for big cities, such as Beijing, Shanghai, Guangzhou, Chengdu, and Seoul (Table 3). This could be due to the burning of coal in industry, which has high sulfur ratio. On the contrary, the mass concentrations of $\mathrm{NO}_{2}$ were lower than those in Beijing, Shanghai, Guangzhou, Chengdu, and Seoul. It was demonstrated that the air pollution from the exhausts of vehicles was not the main source of pollution in these cities.

In general, the trends for monthly mean concentrations of $\mathrm{SO}_{2}$, $\mathrm{NO}_{2}, \mathrm{PM}_{10}$ and $\mathrm{CO}$ were similar to those for the annual concentrations, as shown in Fig. 3. The mass concentrations of these pollutants were higher in winter and spring than those in summer and autumn, as observed by Wan et al. [21]. However, the variation in $\mathrm{O}_{3}$ concentration showed a different trend, in which, the concentrations were lower in colder months than in the hotter ones. Lu et al. [12] obtained similar results for monthly variations in pollutants' concentrations in Hong Kong. The seasonal variations can be explained by the combined influence of high temperature, rainy weather, and unstable atmospheric conditions in summer, whereas these were caused by low temperature, dry weather and more stable atmospheric conditions during winter.

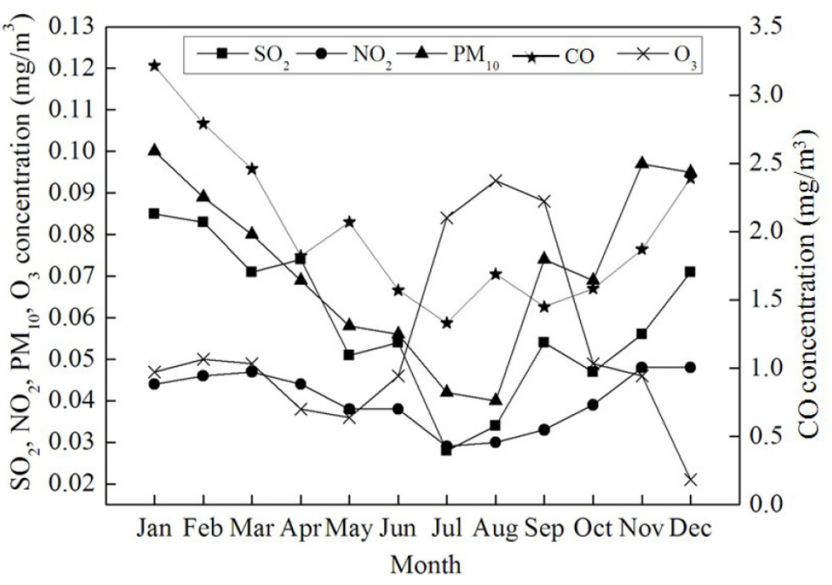

Fig. 3. Monthly mean mass concentrations of five air pollutants in Luzhou City.
Table 3. Comparison of the Air Pollutant Concentrations in Luzhou in 2009 with Other Cities $\left(\mathrm{\mu g} / \mathrm{m}^{3}\right)$

\begin{tabular}{lccccc}
\hline \multicolumn{1}{c}{ City } & $\mathbf{S O}_{\mathbf{2}}$ & $\mathbf{N O}_{\mathbf{2}}$ & $\mathbf{P M}_{\mathbf{1 0}}$ & $\mathbf{C O}$ & $\mathbf{O}_{\mathbf{3}}$ \\
\hline Beijing $^{\mathrm{a}}$ & 34 & 53 & 121 & 1,600 & \\
Shanghai $^{\mathrm{b}}$ & 35 & 53 & 81 & & \\
Guangzhou $^{\mathrm{c}}$ & 39 & 56 & 70 & & \\
Chengdu $^{\mathrm{d}}$ & 38 & 55 & 111 & & \\
Luzhou $^{\mathrm{c}}$ & 59 & 40 & 72 & 2,017 & 54 \\
Tokyo $^{\mathrm{f}}$ & 6 & 43 & 23 & 500 & 4 \\
Seoul $^{\mathrm{g}}$ & 14 & 72 & 54 & 750 & 26 \\
Europe $^{\mathrm{h}}$ & 40 & 24 & 0.025 & 400 & 47 \\
\hline
\end{tabular}

${ }^{a}$ Beijing Environmental Protection Bureau

b Shanghai Environmental Protection Bureau

${ }^{c}$ Guangzhou Environmental Protection Bureau

${ }^{d}$ Chengdu Environmental Protection Bureau

e This study

f Tokyo Bureau of Environment

g Seoul Air Quality Management District

h European Environmental Agency

\subsection{Comparison of Different Air Quality Indices}

API includes only $\mathrm{SO}_{2}, \mathrm{NO}_{2}$ and $\mathrm{PM}_{10}$, whereas $\mathrm{AQI}$ includes two more criteria pollutants $\left(\mathrm{CO}\right.$ and $\mathrm{O}_{3}$ ) on top of the ones present in API. The corresponding mass concentration of $\mathrm{NO}_{2}$ was different between the API and AQI indices. The $\mathrm{NO}_{2}$ concentration was $40 \mu \mathrm{g} / \mathrm{m}^{3}$, and $80 \mu \mathrm{g} / \mathrm{m}^{3}$ for Grade-I and Grade-II in AQI, respectively, whereas the values for $\mathrm{NO}_{2}$ mass concentration in API were 80 $\mu \mathrm{g} / \mathrm{m}^{3}$ and $120 \mu \mathrm{g} / \mathrm{m}^{3}$ for Grade-I and Grade-II, respectively. NAQI also consists of five air pollutants, namely the $\mathrm{SO}_{2}, \mathrm{NO}_{2}, \mathrm{PM}_{10}$, $\mathrm{CO}$, and $\mathrm{O}_{3}$. However, the corresponding mass concentrations of these five air pollutants were only based on the daily average concentrations in Grade-I of NAAQS. The contributions of these five air pollutants to air quality were considered in NAQI and emphasized on the importance of NAAQS.

According to 2009 air quality monitoring data in Luzhou, three different air-quality indices were calculated on daily basis. According to the API values, the number of days monitored were 99, 247 and 19 for Grades I, II and III, respectively. The number of days for which the air quality was good and/or moderate was 346 (94.8\%). This means that, the number of days when API > 100 accounted for only $5.2 \%$ of the total number of days, as shown in Fig. 4. According to AQI values, the number of days were 63, 274 and 28 for Grades I, II and III, respectively. Compared to API, the number of days for good air quality decreased to 36 , whereas the number of days for Grades II and III increased to 27 and 9, respectively. The number of days when AQI $>100$ was 28 and accounted for $7.7 \%$ of the total number of days.

According to NAQI values, the number of days were 23, 159, 116, 44, 22 and 1 for Grades I, II, III, IV, V and VI, respectively. Six grades of air quality were obtained using the NAQI method. According to NAQI values, there were 183 days when NAQI > 100 , and these accounted for $50.1 \%$ of the total number of days in 2009. The maximum NAQI value was 330 , which was observed on November 11, 2009. The mass concentration of $\mathrm{PM}_{10}$ was 4.7 times higher than that of the Grade I concentration of NAAQS. 


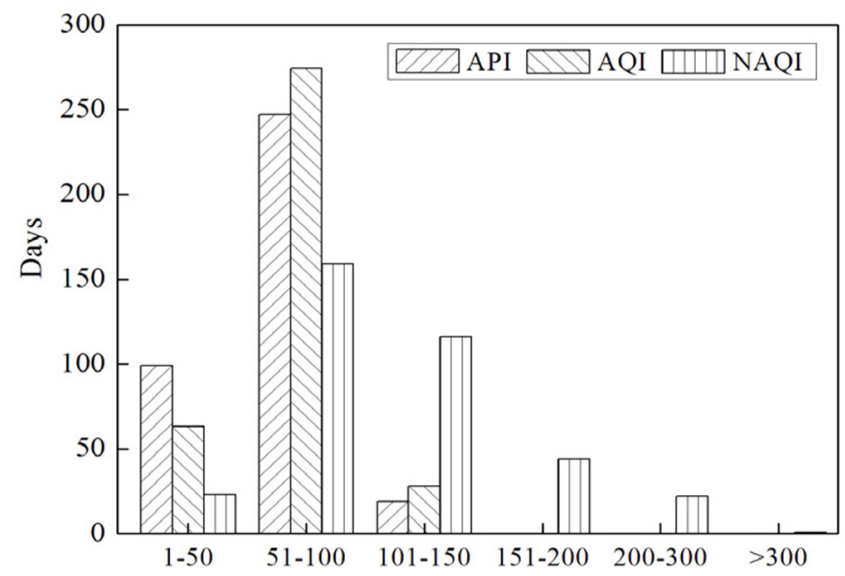

Fig. 4. Comparison of air quality index values.

Meanwhile the maximum value for both API and AQI was 144 on the same day in 2009, and were caused by $\mathrm{PM}_{10}$ pollution. This was due to the reason that particulate matter was produced from burning wood in cold days (for heating purposes), due to which, the air diffused weakly. In short, the urban ambient air quality was the best for API, better for AQI and bad for NAQI as per the results obtained in the current work. Similar conclusions were made and reported by Kyrkilis et al. [22]. Therefore, to a certain extent, the fact whether the air quality is good or bad depends on the assessment method used.

\subsection{Comparison of the Primary Pollutants}

The pollutant of maximum index value was regarded as the primary pollutant when either API or AQI value was more than 50 . Meanwhile, $\mathrm{SO}_{2}, \mathrm{NO}_{2}, \mathrm{PM}_{10}$, $\mathrm{CO}$ and $\mathrm{O}_{3}$ were in turn termed as the primary pollutants when their values were the same. The difference is that, all the pollutants with $P_{i .}$ values of more than 1.0, were regarded as the primary pollutants.

According to the API values of Luzhou in 2009, both $\mathrm{SO}_{2}$ and $\mathrm{PM}_{10}$ were the primary pollutants, whereas $\mathrm{NO}_{2}$ did not appear as the primary pollutant during the time considered in the study, as shown in Fig. 5. There were $79 \mathrm{~d}$ and $187 \mathrm{~d}$ when they were regarded as the primary pollutants, and accounted for $21.6 \%$ and $51.2 \%$ of the total days, respectively.

According to the AQI values, all five air pollutants, which were regarded as the primary pollutants, appeared in the results. The days when $\mathrm{SO}_{2}, \mathrm{NO}_{2}, \mathrm{PM}_{10}$, $\mathrm{CO}, \mathrm{O}_{3}$ were regarded as primary pollutants were 52, 26, 135, 57, and 29, respectively. In addition, $\mathrm{PM}_{10}$ accounted for $37.0 \%$ of the total days. This value was more than one third of the days for the primary pollutants. It is important to note that $\mathrm{NO}_{2}$ and $\mathrm{CO}$, which were mainly emitted by automobiles, showed up in the results, and accounted for $7.1 \%$ and $15.6 \%$ of the total days, respectively. In the secondary air pollutants, $\mathrm{O}_{3}$ accounted for $7.9 \%$ of the total days, which were $29 \mathrm{~d}$ as per the AQI values. The days for which the air quality was "less than good" (API, AQI or NAQI > 50) were more in AQI than in API. There were $302 \mathrm{~d}$ in AQI and $266 \mathrm{~d}$ in API. This meant that, according to AQI, the ambient air quality became worse and more air pollutants caused air pollution in Luzhou, China. However, the main difference was that more air pollutants were regarded

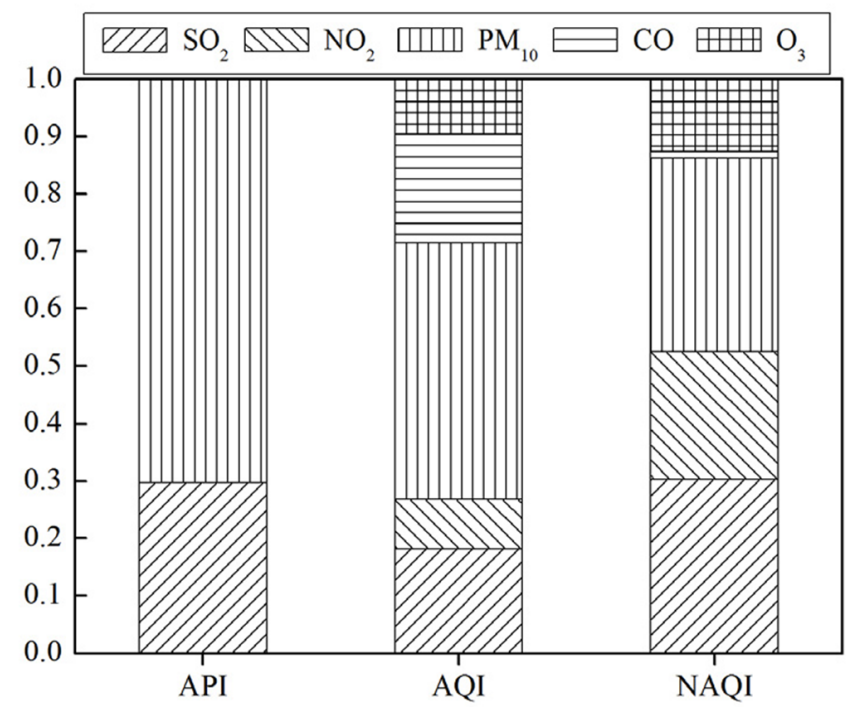

Fig. 5. Comparison of primary pollutants.

as primary pollutants in AQI. $\mathrm{NO}_{2}$ did not appear in the API as primary pollutant; however, it remained primary pollutant for 26 $\mathrm{d}$ in AQI. The reason of the difference was stricter air quality standard set in AQI. The Grade II levels for $\mathrm{NO}_{2}$ were $80 \mu \mathrm{g} / \mathrm{m}^{3}$ in AQI and $120 \mu \mathrm{g} / \mathrm{m}^{3}$ in API. Therefore, it can be seen that, for API or AQI, the level of air quality standard and the kinds of air pollutants were very important. An et al. [23] suggested that major efforts need to be made on the standard-setting process to achieve the lowest concentrations for public health priorities. In this regard, the World Health Organization's (WHO) air quality guidelines are worth referencing.

Since the concentration levels and kinds of air pollutants play a key role in API or AQI indices. Therefore, the effects of air quality standards and all kinds of air pollutants should be emphasized. NAQI takes into account the air quality standards and five air pollutants. The last index value was the maximum for AQI or API, whereas the effects of other air pollutants having smaller values were ignored. In NAQI, the last index value was equal to the sum of sub-NAQI values. There were $342 \mathrm{~d}$ when NAQI > 50 in NAQI, which consisted of 192 (52.6\%) d for $\mathrm{PM}_{10}, 98$ (26.8\%) $\mathrm{d}$ for $\mathrm{SO}_{2}, 27$ (7.4\%) d for $\mathrm{O}_{3}$ and 25 (6.8\%) d for $\mathrm{NO}_{2}$. In addition, CO did not appear as the primary pollutant in NAQI during the time period considered in the current work, although it appeared in AQI. This could be due to the reason that the concentration limits $\left(4,000 \mu \mathrm{g} / \mathrm{m}^{3}\right)$ for Grades I and II were the same in NAAQS. The mass concentration levels of all other air pollutants were higher than the limit level of Grade-I, while the concentration levels of CO were lower than the limit level of Grade-I. Generally, the primary pollutants were obviously different due to three AQIs.

\subsection{Assessment of Three Air Quality Indices}

The air quality standard levels in AQI were stricter than those in API. In addition, AQI contained additional air pollutants which could be considered as primary pollutants. Comparing the two indices, NAQI synthesized five air pollutants, such as $\mathrm{SO}_{2}, \mathrm{NO}_{2}$, $\mathrm{PM}_{10}$, $\mathrm{CO}$ and $\mathrm{O}_{3}$ and were calculated based on the ratio of each 
Table 4. Correlation Analysis between Three Air Quality Indexes and the Air Pollutant Concentrations

\begin{tabular}{|c|c|c|c|c|c|}
\hline \multicolumn{2}{|c|}{ Index Pollutant } & \multirow{2}{*}{$\begin{array}{c}\text { Regression equation } \\
\mathrm{y}=0.0010 \mathrm{x}-0.0039\end{array}$} & \multirow{2}{*}{$\begin{array}{c}\mathbf{R}^{2} \\
0.6504\end{array}$} & \multirow{2}{*}{$\begin{array}{c}\text { Standard deviation } \\
0.0161\end{array}$} & \multirow{2}{*}{$\begin{array}{c}\text { Significant coefficient } \\
0.806^{* *}\end{array}$} \\
\hline & $\mathrm{SO}_{2}$ & & & & \\
\hline \multirow[t]{4}{*}{ API } & $\mathrm{NO}_{2}$ & $\mathrm{y}=0.0004 \mathrm{x}+0.0164$ & 0.4948 & 0.0084 & $0.703^{* *}$ \\
\hline & $\mathrm{PM}_{10}$ & $y=0.0018 x-0.0368$ & 0.9063 & 0.0123 & $0.952^{* *}$ \\
\hline & $\mathrm{SO}_{2}$ & $\mathrm{y}=0.0010 \mathrm{x}-0.0095$ & 0.5452 & 0.0184 & $0.738^{* *}$ \\
\hline & $\mathrm{NO}_{2}$ & $\mathrm{y}=0.0004 \mathrm{x}+0.0135$ & 0.4377 & 0.0089 & $0.662^{* *}$ \\
\hline \multirow[t]{5}{*}{ AQI } & $\mathrm{PM}_{10}$ & $y=0.0018 x-0.0506$ & 0.8114 & 0.0174 & $0.901^{* *}$ \\
\hline & $\mathrm{CO}$ & $y=0.0259 x+0.2720$ & 0.4087 & 0.6179 & $0.639^{* \star}$ \\
\hline & $\mathrm{O}_{3}$ & $\mathrm{y}=0.0001 \mathrm{x}+0.0460$ & 0.0058 & 0.0311 & 0.076 \\
\hline & $\mathrm{SO}_{2}$ & $y=0.0004 x+0.0106$ & 0.6626 & 0.0158 & $0.814^{* *}$ \\
\hline & $\mathrm{NO}_{2}$ & $y=0.0002 x+0.0218$ & 0.5087 & 0.0083 & $0.713^{* *}$ \\
\hline \multirow[t]{3}{*}{ NAQI } & $\mathrm{PM}_{10}$ & $y=0.0008 x-0.0121$ & 0.9335 & 0.0103 & $0.966^{* *}$ \\
\hline & $\mathrm{CO}$ & $y=0.0086 x+1.0588$ & 0.3015 & 0.6715 & $0.549^{* *}$ \\
\hline & $\mathrm{O}_{3}$ & $y=-9.5 \times 10^{-6} x+0.0551$ & 0.0002 & 0.0312 & -0.016 \\
\hline
\end{tabular}

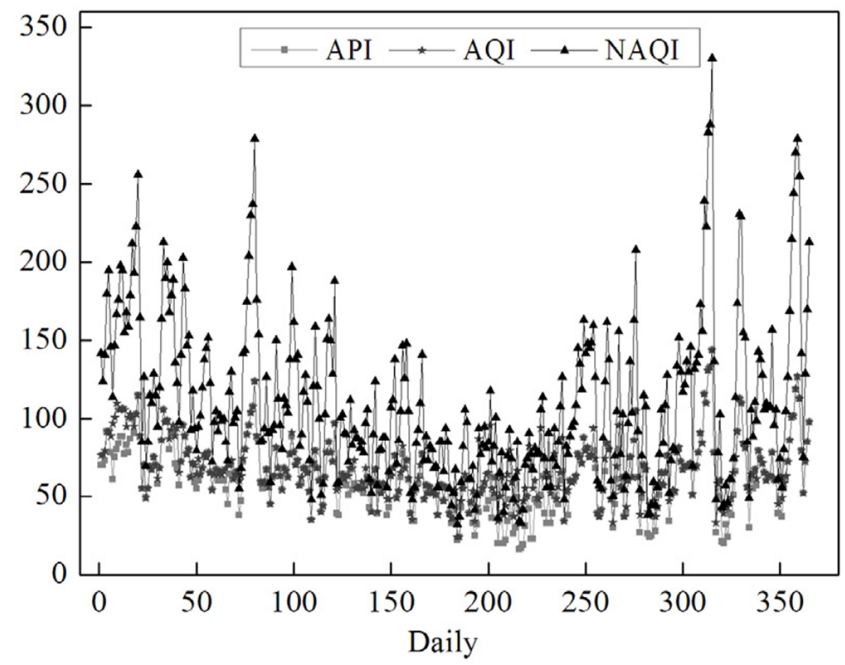

Fig. 6. Trends of the three air quality indexes in 2009.

air pollutant's concentration and corresponding first level in NAAQS. According to the calculated results of three AQIs, the trends of daily index values were not different, as shown in Fig. 6. The major difference was that the NAQI values were the greatest in all three AQIs, whereas API values were the minimum. Therefore, the NAQI values can accurately reflect the air quality. The correlation analysis between three AQIs and the concentrations of five criteria air pollutants are listed in Table 4. The air pollutants can be ranked according to decreasing correlation coefficients as $\mathrm{PM}_{10}$, $\mathrm{SO}_{2}$ and $\mathrm{NO}_{2}$. This is mainly due to the reason that the source of pollution is industrial coal combustion and the exhausts from automobiles. However, the correlation coefficients for $\mathrm{PM}_{10}, \mathrm{SO}_{2}$ and $\mathrm{NO}_{2}$ concentration are higher in NAQI than those in AQI, and API. These results illustrated that NAQI can accurately reflect the urban ambient air quality due to $\mathrm{PM}_{10}, \mathrm{SO}_{2}$ and $\mathrm{NO}_{2}$. According to the correlation coefficients between NAQI, AQI and CO concentrations, AQI can reflect the urban air quality much better than
NAQI. This is due to the reason that CO is regarded as a primary pollutant in AQI, and not in NAQI. On the contrary, both NAQI and AQI cannot reflect the $\mathrm{O}_{3}$ concentrations due to secondary pollution. The AQI, which can represent air quality due to second air pollution, should be studied in more details.

\section{Conclusions}

In China, API consists of $\mathrm{SO}_{2}, \mathrm{NO}_{2}$ and $\mathrm{PM}_{10}$ and has been used to inform citizens of the urban ambient air quality since 2000 . AQI has additional pollutants of $\mathrm{CO}, \mathrm{O}_{3}$ and $\mathrm{PM}_{2.5}$ since 2016. The two kinds of AQIs only consider the maximum index value of an air pollutant, whereas the contributions and combined effects of other air pollutants were ignored. Due to these reasons, NAQI included the combined effects of all air pollutants, and has the advantage to be calculated in a simple way according to NAAQS.

The data of air pollutant concentrations, including $\mathrm{SO}_{2}, \mathrm{NO}_{2}$, $\mathrm{PM}_{10}$, $\mathrm{CO}$ and $\mathrm{O}_{3}$, were collected daily in 2009 at four environmental monitoring sites in Luzhou, which is a southern city of Sichuan basin in China. The statistical results showed that the annual mass concentrations of $\mathrm{SO}_{2}, \mathrm{CO}$, and $\mathrm{O}_{3}$ in Luzhou were higher than those in other big cities (Beijing, Shanghai, Guangzhou, Chengdu, and Seoul). On the contrary, the concentrations of $\mathrm{NO}_{2}$ and $\mathrm{PM}_{10}$ were lower than the values in these big cities. In addition, all air pollutants except $\mathrm{O}_{3}$ had monthly variations, which showed that the concentrations of these pollutants were found to be higher in winter and spring than those in summer and autumn.

According to these air pollutants' concentration data, three different AQIs of API, AQI and NAQI were compared. The results showed that there were $19 \mathrm{~d}$ (5.2\% of the total days) in API, $28 \mathrm{~d}(7.7 \%$ of the total days) in AQI and $183 \mathrm{~d}$ (50.1\% of the total days) in NAQI when these indices were higher than 100 . Overall, depending on the NAQI values, the urban air quality became worse. Both $\mathrm{PM}_{10}$ and $\mathrm{SO}_{2}$ in API, all five air pollutants in AQI, and four air pollutants except for the $\mathrm{CO}$ in NAQI were regarded as the primary 
pollutants. $\mathrm{PM}_{10}$ was the main primary pollutant in three AQIs, which accounted for $51.2 \%$ (of total days), $37.0 \%$ (of total days) and $52.6 \%$ (of total days), respectively. Therefore, the particulate matter's pollution was very significant in Luzhou and stricter pollution control measures should be implemented to control it.

The variation trends of three AQIs were not different, though the daily variation of NAQI in 2009 was always higher than those for the AQI and API. The correlation between NAQI and air pollutants' concentration was more obvious than the other two indices. Based upon the results, it can safely be said that NAQI can satisfactorily and systematically reflect the urban ambient air quality situation.

\section{Acknowledgments}

This work was supported by the Science \& Technology Department of Sichuan Province (2015JY0094, 2017KZ0041), and Chemical Synthesis and Pollution Control Key Laboratory of Sichuan Province (CSPC2014-4-2). The authors wish to acknowledge the support obtained from Luzhou Environmental Protection Agency in the form of urban ambient air quality monitoring data.

\section{References}

1. Chan CK, Yao XH. Air pollution in mega cities in China. Atmos. Environ. 2008;42:1-42.

2. Hopke PK, Cohen DD, Begum BA, et al. Urban air quality in the Asian region. Sci. Total. Environ. 2008;402:103-112.

3. Mandal T, Gorai AK, Pathak G. Development of fuzzy air quality index using soft computing approach. Environ. Monit. Assess. 2012;184:6187-6196.

4. Plaia A, Ruggieri M. Air quality indices: A review. Rev. Environ. Sci. Biotechnol. 2011;10:165-179.

5. Bodnar O, Cameletti M, Fassò A, Schmid W. Comparing air quality in Italy, Germany and Poland using BC indexes. Atmos. Environ. 2008;42:8412-8421.

6. Cairncross KE, John J, Zunckel M. A novel air pollution index based on the relative risk of daily mortality associated with short-term exposure to common air pollutants. Atmos. Environ. 2007;41:8442-8454.

7. Cheng WL, Chen YS, Zhang JF, Lyons TJ, Pai JL, Chang SH. Comparison of the revised air quality index with the PSI and AQI indices. Sci. Total. Environ. 2007;382:191-198.

8. Cooper MJ, Martin RV, Donkelaar AV, Lamsal L, Brauer M, Brook JR. A satellite-based multi-pollutant index of global air quality. Environ. Sci. Technol. 2012;46:8523-8524.

9. Dimitriou K, Paschalidou AK, Kassomenos PA. Assessing air quality with regards to its effect on human health in the European Union through air quality indices. Ecol. Indic. 2013;27:108-115.

10. Elshout S, Léger K, Nussio F. Comparing urban air quality in Europe in real time: A review of existing air quality indices and the proposal of a common alternative. Environ. Int. 2008;34:720-726.

11. Kassomenos PA, Kelessis A, Petrakakis M. Air quality assessment in a heavily polluted urban Mediterranean environment through air quality indices. Ecol. Indic. 2012;18:259-268.

12. Lu WZ, He HD, Leung TY. Assessing air quality in Hong Kong: A proposed, revised air pollution index (API). Build. Environ. 2011;46:2562-2569.

13. Mayer H, Holst J, Schindler D, Ahrens D. Evolution of the air pollution in SW Germany evaluated by the long-term air quality index LAQx. Atmos. Environ. 2008;42:5071-5078.

14. Mohan M, Kandya A. An analysis of the annual and seasonal trends of air quality index of Delhi. Environ. Monit. Assess. 2007;131:267-277.

15. Nagendra SSM, Venugopal K, Jones SL. Assessment of air quality near traffic intersections in Bangalore City using air quality indices. Transport. Res. D-TR. E. 2007;12:167-176.

16. Zhou K, Ye YH, Liu Q, Liu AJ, Peng SL. Evaluation of ambient air quality in Guangzhou, China. J. Environ. Sci. 2007;19: 432-437.

17. Bishoi B, Prakash A, Jain VK. A comparative study of air quality index based on factor analysis and US-EPA methods for an urban environment. Aerosol Air Qual. Res. 2009;9:1-17.

18. Plaia A, Salvo FD, Ruggieri M, Agró G. A multisite-multipollutant air quality index. Atmos. Environ. 2013;70:387-391.

19. Sicard P, Lesne O, Alexandre N, Mangin A, Collomp R. Air quality trends and potential health effects-development of an aggregate risk index. Atmos. Environ. 2011;45:1145-1153.

20. Sowlata MH, Gharibi H, Yunesian M, Mahmoudi MT, Lotfi S. A novel, fuzzy-based air quality index (FAQI) for air quality assessment. Atmos. Environ. 2011;45:2050-2059.

21. Wan JM, Lin M, Chan CY, et al. Change of air quality and its impact on atmospheric visibility in central-western Pearl River Delta. Environ. Monit. Assess. 2011;172:339-351.

22. Kyrkilis G, Chaloulakou A, Kassomenos PA. Development of an aggregate air quality index for an urban Mediterranean agglomeration: Relation to potential health effects. Environ. Int. 2007;33:670-676.

23. An XQ, Hou Q, Li N, Zhai S. Assessment of human exposure level to $\mathrm{PM}_{10}$ in China. Atmos. Environ. 2013;70:376-386. 